\title{
Lacticaseibacillus casei ATCC 393 Cannot Colonize the Gastrointestinal Tract of Crucian Carp
}

\author{
Hongyu Zhang ${ }^{1,2} \mathbb{D}^{\text {, Xiyan Mu }}{ }^{1,2}$, Hongwei Wang ${ }^{2}$, Haibo Wang ${ }^{1,2}$, Hui Wang ${ }^{1,2}$, Yingren Li ${ }^{1,2}$, \\ Yingchun $\mathrm{Mu}^{2,3, *}$, Jinlong Song ${ }^{2,3, *}$ and Lei $\mathrm{Xia}^{2, *}$
}

1 Fishery Resource and Environment Research Center, Chinese Academy of Fishery Sciences, Beijing 100141, China; zhanghy@cafs.ac.cn (H.Z.); muxiyan@cafs.ac.cn (X.M.); xuehu1110@aliyun.com (H.W.); wanghui@cafs.ac.cn (H.W.); liyr@cafs.ac.cn (Y.L.)

2 Chinese Academy of Fishery Sciences, Beijing 100141, China; wanghongwei@cafs.ac.cn

3 Key Laboratory of Control of Quality and Safety for Aquatic Products (Ministry of Agriculture and Rural Affairs), Chinese Academy of Fishery Sciences, Beijing 100141, China

* Correspondence: muyc@cafs.ac.cn (Y.M.); songj1@cafs.ac.cn (J.S.); xialei666@126.com (L.X.)

check for

updates

Citation: Zhang, H.; Mu, X.; Wang, H.; Wang, H.; Wang, H.; Li, Y.; Mu, Y.; Song, J.; Xia, L. Lacticaseibacillus casei ATCC 393 Cannot Colonize the Gastrointestinal Tract of Crucian Carp. Microorganisms 2021, 9, 2547. https://doi.org/10.3390/ microorganisms 9122547

Academic Editors: Konstantinos Ar. Kormas and James S. Maki

Received: 30 September 2021 Accepted: 3 December 2021 Published: 9 December 2021

Publisher's Note: MDPI stays neutral with regard to jurisdictional claims in published maps and institutional affiliations.

Copyright: (c) 2021 by the authors. Licensee MDPI, Basel, Switzerland. This article is an open access article distributed under the terms and conditions of the Creative Commons Attribution (CC BY) license (https:// creativecommons.org/licenses/by/ $4.0 /)$.

\begin{abstract}
Lactic acid bacteria (LAB) are commonly applied to fish as a means of growth promotion and disease prevention. However, evidence regarding whether LAB colonize the gastrointestinal (GI) tract of fish remains sparse and controversial. Here, we investigated whether Lacticaseibacillus casei ATCC 393 (Lc) can colonize the GI tract of crucian carp. Sterile feed irradiated with ${ }^{60}$ Co was used to eliminate the influence of microbes, and $100 \%$ rearing water was renewed at 5-day intervals to reduce the fecal-oral circulation of microbes. The experiment lasted 47 days and was divided into three stages: the baseline period ( 21 days), the administration period ( 7 days: day -6 to 0 ) and the post-administration period (day 1 to 19). Control groups were fed a sterile basal diet during the whole experimental period, whereas treatment groups were fed with a mixed diet containing Lc $\left(1 \times 10^{7} \mathrm{cfu} / \mathrm{g}\right)$ and spore of Geobacillus stearothermophilus $\left(\mathrm{Gs}, 1 \times 10^{7} \mathrm{cfu} / \mathrm{g}\right)$ during the administration period and a sterile basal diet during the baseline and post-administration periods. An improved and highly sensitive selective culture method (SCM) was employed in combination with a transit marker (a Gs spore) to monitor the elimination of Lc in the GI tract. The results showed that Lc ( $<2 \mathrm{cfu} /$ gastrointestine) could not be detected in any of the fish sampled from the treatment group 7 days after the cessation of the mixed diet, whereas Gs could still be detected in seven out of nine fish at day 11 and could not be detected at all at day 15. Therefore, the elimination speed of Lc was faster than that of the transit marker. Furthermore, high-throughput sequencing analysis combined with SCM was used to reconfirm the elimination kinetics of Lc in the GI tract. The results show that the Lc in the crucian carp GI tract, despite being retained at low relative abundance from day $7(0.11 \% \pm 0.03 \%)$ to 21 , was not viable. The experiments indicate that Lc ATCC 393 cannot colonize the GI tract of crucian carp, and the improved selective culture in combination with a transit marker represents a good method for studying LAB colonization of fish.
\end{abstract}

Keywords: Lacticaseibacillus casei; colonization; crucian carp; gastrointestinal tract; ${ }^{60}$ Co irradiation sterilization; transit marker; Geobacillus stearothermophilus; high-throughput sequencing

\section{Introduction}

Given the restrictions and prohibitions regarding the use of chemicals and antibiotics, there is an increasing demand for safe, cost-effective, and environmentally friendly feed supplements that possess exceptional benefits for farmed fish such as phytogenics, prebiotics and probiotics [1]. One of therapeutic benefits of probiotics are that they can colonize or temporally colonize gastrointestinal (GI) tract and thereby modulate the intestinal microbiota via competitive adherence and exclusion, resulting in the production of beneficial substances for the host [2,3]. Colonization is one of the most important characteristics when evaluating the application of probiotics in animal rearing. LAB are one of the most widely 
used and studied bacteria in aquaculture, but their colonization in the intestinal tract of fish remains highly debated. Tian et al. [4] stated that Lacticaseibacillus casei CC16 can colonize the intestines of common carp. Other papers have reported that Pediococcus acidilactici (Bactocell ${ }^{\circledR}$, Lallemand Inc., Montreal, QC, Canada) [5], Bacillus paralicheniformis FA6 [6], Lactiplantibacillus plantarum G1 [7], Lacticaseibacillus casei ATCC 393 [8], Latilactobacillus sakei CLFP 202 [9], Lactococcus lactis CLFP 100 [9] and Leuconostoc mesenteroides CLFP 196 [9] can also colonize the GI tract of goldfish, grass carp, shabout fish and rainbow trout. However, some papers have shown that probiotic strains, including Lactobacillus, in the GI tract rapidly decreases following the withdrawal of supplementation [10-16], indicating their transient nature. Meanwhile, Ringø et al. [17] raised the following question: "Are probiotics permanently colonizing the GI tract?".

Colonization was defined by Conway and Cohen as the indefinite persistence of a particular bacterial population without the reintroduction of that bacterium [18]. Most bacterial cells are transiently present in the GI tract of aquatic animals, with the continuous intrusion of microbes from water and food [19]. Commercial feed or homemade feed are usually unsterile except for specific pathogen free (SPF) or gnotobiotic animals [20]. Considering the widespread existence of lactic acid bacteria (LAB) and Bacillus, it is rational to speculate on their existence in aquafeed. The transient microbes in the GI tract enter water with feces and can then be reintroduced to that same GI tract. However, in probiotic colonization-related studies, little attention has been paid to the influence of microbes originating from feed and water, resulting in a conclusion that ignores the prerequisite for colonization, i.e., that it occurs "without the reintroduction of that bacterium". In addition, the monitoring time for the persistence of probiotic microbes in the GI tract has often been insufficient, and there has been an absence of transit markers for evaluating the clearance time for transient microbes [21].

Colonization is a very important characteristic for screening additive strains and studying the mechanisms of probiotic action, but is associated with several significant challenges. First, the target bacteria being found in the water and diet can interfere with the colonization study. Second, lacking suitable methods for colonization study, some molecular methods such as 16S rRNA amplicon technology based on DNA samples cannot tell whether the bacteria are alive or dead. Third, once the probiotic supplementation has ceased, the proportion of the target strain may remain at a very low level [22], requiring a detection method with higher sensitivity for viable cells.

L. casei $(\mathrm{Lc})$ is one of the species commonly used in aquaculture $[4,17]$ and has shown some beneficial properties when applied to fish [23,24]. However, whether bacteria colonize the GI tract of fish has been unclear. To solve the issues above, the interfering microbes in feed and water were monitored and controlled, a transit marker was introduced, and an improved and highly sensitive selective culture method and high-throughput sequencing were both used to investigate whether L. casei can "truly" colonize the GI tract of crucian carp.

\section{Materials and Methods}

\subsection{Bacteria Strains and Culture Condition}

Lacticaseibacillus casei (Lc) ATCC 393 and Geobacillus stearothermophilus (Gs) ATCC 7953, were purchased from the China Center of Industrial Culture Collection and maintained with regular procedures.

Lc: The Lc strain was grown in MRS (De Man, Rogosa and Sharpe, Oxoid) broth at $37^{\circ} \mathrm{C}$ overnight without agitation. The cells were harvested by centrifugation $(5000 \times g, 5 \mathrm{~min})$, resuspended in normal saline $(0.85 \%(w / v) \mathrm{NaCl}, \mathrm{pH} 7.5)$ and adjusted to the necessary concentration.

Gs: The bacterial lawn grown on nutrient agar (NA, Aobox) supplemented with $18 \mu \mathrm{M} / \mathrm{L}$ $\mathrm{MnSO}_{4}$ at $57{ }^{\circ} \mathrm{C}$ for 4 days was harvested and washed twice with normal saline and then resuspended in normal saline. After inactivation vegetative cells incubated in a water bath at $90{ }^{\circ} \mathrm{C}$ for $30 \mathrm{~min}$, the Gs spore suspension was centrifuged, washed twice with normal saline again, and then adjusted to the necessary concentration. 


\subsection{Experiment Diet}

For the sterilized diet (basal diet), five commercial aquafeeds were sterilized by ${ }^{60} \mathrm{Co}$ irradiation at $26.0 \mathrm{kGy}$, after which the efficacy of the sterilization was evaluated. The feed pellets with or without sterilization were homogenized and spread on nutrient agar and MRS agar with a $\mathrm{pH}$ of 5.4-5.5. The nutrient agar was incubated at 37 and $57^{\circ} \mathrm{C}$ for 3 days to count the general heterotrophic bacteria and thermophiles, respectively. MRS agar was incubated at $37^{\circ} \mathrm{C}$ for 3 days to count LAB. The colony number was counted to calculate the bacterial concentration in feed, and representative colonies with differing morphologies were selected for identification by $16 \mathrm{~S}$ rRNA gene sequencing. Bacterial DNA was extracted using the TIANamp Bacteria DNA Kit (Tiangen) according to the manufacturer's protocol. The DNA samples were submitted to the Rui Biotech, Inc. (Beijing, China) for PCR amplification and sequencing. The $16 \mathrm{~S}$ ribosomal RNA gene from each sample were amplified and sequenced using the bacterial universal primer 27F (5'-AGAGTTTGATCCTGGCTCAG-3') and 1492R ( $5^{\prime}$-TACGGCTACCTTGTTACGA CTT- $\left.{ }^{\prime}\right)$. Then the $16 \mathrm{~S}$ sequences alignments were performed using BLAST based on $16 \mathrm{~S}$ ribosomal RNA sequences database of NCBI. Sterilized diet No. 2 (Beijing Fangteqi Feed Co., Ltd., Beijing, China, Table A1) was used in the experiment.

For the Mixed diet, Lc and Gs suspension were prepared and sprayed on the sterile basal feed to achieve a final concentration of $1 \times 10^{7} \mathrm{cfu} / \mathrm{g}$ in Experiment 1 . The final concentrations of Lc and Gs were $2 \times 10^{9} \mathrm{cfu} / \mathrm{g}$ and $1 \times 10^{8} \mathrm{cfu} / \mathrm{g}$ in Experiment 2, respectively. The experimental feed was air-dried in an oven for $10 \mathrm{~min}$ at $37^{\circ} \mathrm{C}$, and sealed and stored at $4{ }^{\circ} \mathrm{C}$. The viable bacterial number in the feed was counted using the plate counting method at the beginning and end of the feeding experiments.

\subsection{Experiment Design and Rearing Conditions}

Two methods were used at two separate experimental phases. First, an improved and highly sensitive selective culture method (SCM) was established to compare the elimination kinetics between Lc and a transit marker (a Gs spore). Second, second-generation sequencing based on an $16 \mathrm{~S}$ rRNA gene amplicon sequencing method (16S) was used to analyze the relative abundance of Lc and Gs. Meanwhile, the whole gastrointestines were sampled at the same time point, and their viable bacteria were monitored using the SCM. The flow chart of design of experiment see Figure A1.

Crucian carp (Carassius auratus) that weighed 20-40 g were obtained from the Beijing Longchi Aquaculture Farm. The fish were distributed into six separate glass aquariums $(300 \mathrm{~L})$ at a density of 24 fish per tank. Three glass aquariums were used for the treatment group (TG) and the others were used for the control group (CG). The study period was divided into three consecutive periods. First was the 21-day long, baseline period, during which the fish from both groups were fasted for 7 days and then acclimatized to the sterile pellet feed at $1.0-1.5 \%$ body weight once a day for 14 days. The last day of this period was defined as day -7 . Next was the 7 day administration period (day -6 to day 0 ) and, finally, the post-administration period (19 days during Experiment 1 and 21 days during Experiment 2). During the administration period, the mixed diet was orally administered in both experiments for 7 days. The basal diet was used in all other periods, including the baseline period and the post-administration period. Meanwhile, the basal diet was used throughout the whole experiment in the control group. A total of nine fish with three in each tank were taken at days $-7,0,7,11,15$ and 19 during Experiment 1, whereas nine fish (six for the SCM and three for 16S) were collected at five time points during Experiment 2 (that is, days $-7,0,7,14$ and 21 ).

During the baseline and post-administration periods, $100 \%$ of the water was renewed every 5 days in both experiments. Tap water was equilibrated to room temperature and aerated for $48 \mathrm{~h}$ before use. The physical parameters of the water were as follows: temperature $22-25^{\circ} \mathrm{C}, \mathrm{pH} 8.0-9.0$, and dissolved oxygen $>6 \mathrm{mg} / \mathrm{L}$. 


\subsection{Monitoring Lc and Thermophiles in Water}

During the whole experimental period, $2 \mathrm{~mL}$ of water was sampled from the fish tanks every 3 days. A total of $1 \mathrm{~mL}$ water was spread on two MRS agar plates (pH 5.4-5.5, $500 \mu \mathrm{L}$ on each plate), and the remaining $1 \mathrm{~mL}$ was spread on two nutrient agar plates (500 $\mu \mathrm{L}$ on each plate). MRS agar was incubated at $37^{\circ} \mathrm{C}$ for 7 days. Nutrient agar was incubated at $57^{\circ} \mathrm{C}$ for 2 days. The colonies were identified by $16 \mathrm{~S}$ RNA gene sequencing.

\subsection{Experiment 1: The Improved, Highly Sensitive Selective Culture Method}

The $\mathrm{pH}$ of MRS medium was adjusted to 5.4-5.5 for the selective culture of Lc. The spore of Gs was used as the transit marker $[21,25,26]$.

\subsubsection{Gastrointestine Homogenate Preparations}

The fish were sacrificed at the sampling point, and close to the entire GI tract, from the esophagus to the anus, was aseptically removed. Then, an ice-cold normal saline solution was added to make a $10 \%(w / w)$ homogenate using a glass homogenizer. Meanwhile, the effect of the $10 \%$ GI tract homogenate on Lc and Gs and their respective media were evaluated as described below.

The Lc suspension was inoculated into the $10 \%$ GI tract homogenate of the crucian carp and normal saline at $1 \%(v / v)$ to a final concentration of $5 \times 10^{2} \mathrm{cfu} / \mathrm{mL}$. A $200 \mu \mathrm{L}$ aliquot of homogenate containing Lc was spread on MRS agar with a pH of 5.4-5.5. A $200 \mu \mathrm{L}$ aliquot of normal saline control containing Lc was spread on regular MRS agar. The plates were incubated at $37^{\circ} \mathrm{C}$ for 7 days. Then, the colony number was counted to calculate the growth rate. The colony was identified at the species level by 16S RNA gene sequencing technology.

The Gs suspension was inoculated into the $10 \%$ GI tract homogenate of the crucian carp and the normal saline at $1 \%(v / v)$, achieving a final concentration of $1 \times 10^{3} \mathrm{cfu} / \mathrm{mL}$. Aliquots $(100 \mu \mathrm{L})$ of homogenate and normal saline containing Gs were spread on the nutrient agar. The plates were incubated at $57^{\circ} \mathrm{C}$ for 2 days, and the colony number was then counted to calculate the growth rate. The colony was identified at the species level by $16 \mathrm{~S}$ rRNA gene sequencing technology.

The growth rate was assessed by Equation(1).

Growth rate $=$ (the colony number of experiment group / the average colony number of control group) $\times 100 \%$

\subsubsection{Dynamics of Lc and the Transit Marker in the Gastrointestinal Tract}

The GI tract was removed at the appropriate sample time point, and homogenate was prepared as described above (2.5.1); half was spread on nutrient agar (100 $\mu \mathrm{L}$ per plate), and the other half was spread on MRS agar with a pH of 5.4-5.5 (200 $\mu \mathrm{L}$ per plate). The detection limit for Lc and Gs was $2 \mathrm{cfu} /$ gastrointestine. In cases where no LAB grew on the MRS agar, an additional six fish were sacrificed, and all GI tract homogenates were spread on MRS with a $\mathrm{pH}$ of 5.4-5.5 to reach a detection limit of $1 \mathrm{cfu} /$ gastrointestine.

Generally, 20-30 plates are required for a $5 \mathrm{~mL}$ GI tract homogenate to reach a detection limit of $2 \mathrm{cfu} /$ gastrointestine. The colonies were identified by microscopic examination and/or $16 \mathrm{~S}$ rRNA gene sequencing. The sum of the Lc colony number for each plate was the total viable bacteria in the GI tract when all the GI tract homogenate was spread on the plate.

\subsection{Experiment 2: $16 S$ rRNA Gene Amplicon Sequencing Method (16S)}

Sample Collection, DNA Extraction and Bioinformatic Analysis.

Of the nine samples (three fish per replicate) that were randomly selected from each group at each sample time point, six fish were monitored using the SCM as described above (2.5.2) and the other three fish were used for second-generation sequencing. The gastrointestinal contents were removed under sterile conditions. Bacterial DNA was extracted using the E.Z.N.A 
Mag-Bind Soil DNA Kit (Omega, Norcross, GA, USA). The DNA quality and concentrations were measured using a Qubit ${ }^{\circledR} 3.0$ spectrophotometer (Invitrogen, Waltham, MA, USA). The DNA samples were submitted to Sangon Biotech, Inc. (Shanghai, China) for PCR amplification and next-generation sequencing using an Illumina MiSeq platform. The primer sequences (341F (5'-CCTACACGACGCTCTTCCGATCTG(barcode) CCTACGGGNGGCWGCAG-3') and 805R ( $5^{\prime}$-GACTGGAGTTCCTTGGCACCCGA GAATTCCAGACTACHVGGGTATCTAATCC-3')), PCR cleanup, and sequencing were performed and a bioinformatic analysis was conducted as described in our previous study [27].

\subsection{Data Analyses}

Data were analyzed using T-test. A statistical analysis was performed using Microsoft Office Excel 2007(USA) with the level of significance set at $p<0.05$.

\section{Results}

\subsection{Effect of $100 \%$ Water Renewal on Interfering Bacteria}

During the baseline period, no cultivable Lc or thermophiles were detected in the rearing water $(<1 \mathrm{cfu} / \mathrm{mL})$. During the administration period, $0-9 \times 10^{2} \mathrm{cfu} / \mathrm{mL}$ of Lc and $0.1-8 \times 10^{3} \mathrm{cfu} / \mathrm{mL}$ of Gs were detected in the rearing water. No Lc was detected following the cessation of bacterial supplementation and $100 \%$ water renewal up to the end of the experiments. Several Gs colonies were occasionally detected in the first week, whereas no Gs were detected after the second water renewal during the post-administration period.

\subsection{Effect of Sterilizing the Feed with ${ }^{60}$ Co Irradiation}

The bacterial content of the commercial aquafeed is shown in Table A2. There were general heterotrophic bacteria at $10^{4}-10^{6} \mathrm{cfu} / \mathrm{g}$ of the commercial diet, LAB at $10^{2}-10^{4} \mathrm{cfu} / \mathrm{g}$ and thermophiles at $10^{2}-10^{4} \mathrm{cfu} / \mathrm{g}$. Using $16 \mathrm{~S}$ rRNA gene sequencing identification, it was found that the general heterotrophic bacteria were mainly species of the genera Bacillus (including Bacillus licheniformis and Bacillus subtilis), and others include Enterobacter, Parabacillus, Pantoea, etc. The LAB were Pediococcus, Enterococcus and Bacillus coagulans. The thermophiles included mainly Geobacillus, Parageobacillus, and Bacillus. None of these bacteria were detected after ${ }^{60} \mathrm{Co}$ irradiation sterilization.

Meanwhile, the concentration of Gs and Lc in the mixed diet did not attenuate at the end of either experiments (Table A3).

\subsection{Selective Culture for $L A B$ and $G s$}

The $\mathrm{pH}$ of MRS medium was adjusted to 5.4-5.5 for the selective culture of Lc. The MRS agar with a $\mathrm{pH}$ of 5.4-5.5 had high specificity for Lc growth, except for the occasional presence of some fungi and motile bacteria that failed to subculture in the rearing water and the gut at very low doses. There was no significant difference between the regular MRS and the 10\% GI tract homogenate MRS (pH 5.4-5.5) (Figure 1). In other words, the improved MRS agar had a high specificity and sensitivity and was, thus, able to detect the LAB strains used in our study of the GI tract homogenate.

The growth rate of Gs at $57^{\circ} \mathrm{C}$ was $83.78 \% \pm 26.80 \%$ (Figure 2) when suspended in the $10 \%$ GI tract homogenate, which was slightly lower than that of the normal saline control. However, there were no significant differences between the two groups $(p>0.05)$.

\subsection{The Concentration of Lc Changes in the GI Tract of Crucian Carp}

The concentration of Lc and Gs in the GI tract decreased dramatically after the cessation of both bacteria supplements (Figure 3). In the first 3 days, the Lc concentration decreased from $2.6 \times 10^{5}(5.43 \mathrm{log})$ to $20.67(1.32 \mathrm{log}) \mathrm{cfu} /$ gastrointestine, and Lc could not be detected in the GI tracts of two out of nine fish. Seven days after the cessation of the mixed diet, Lc could not be detected in any of the sampled fish ( $<2 \mathrm{cfu} /$ gastrointestine), although Gs was remained detectable up to day 11 (7/9). As can be seen from Figure 3, Lc was eliminated from crucian carp gastrointestine faster than Gs. 


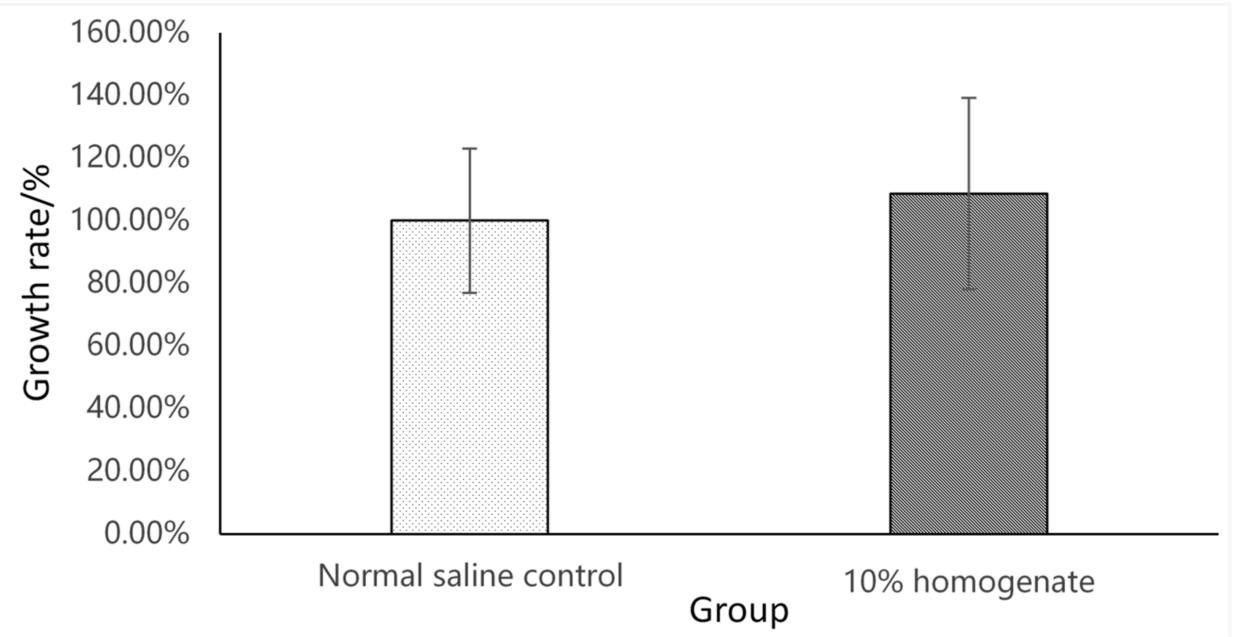

Figure 1. Comparison between the growth rate of L. casei in the normal saline control and 10\% GI tract homogenate $(n=9)$ on the MRS plate.

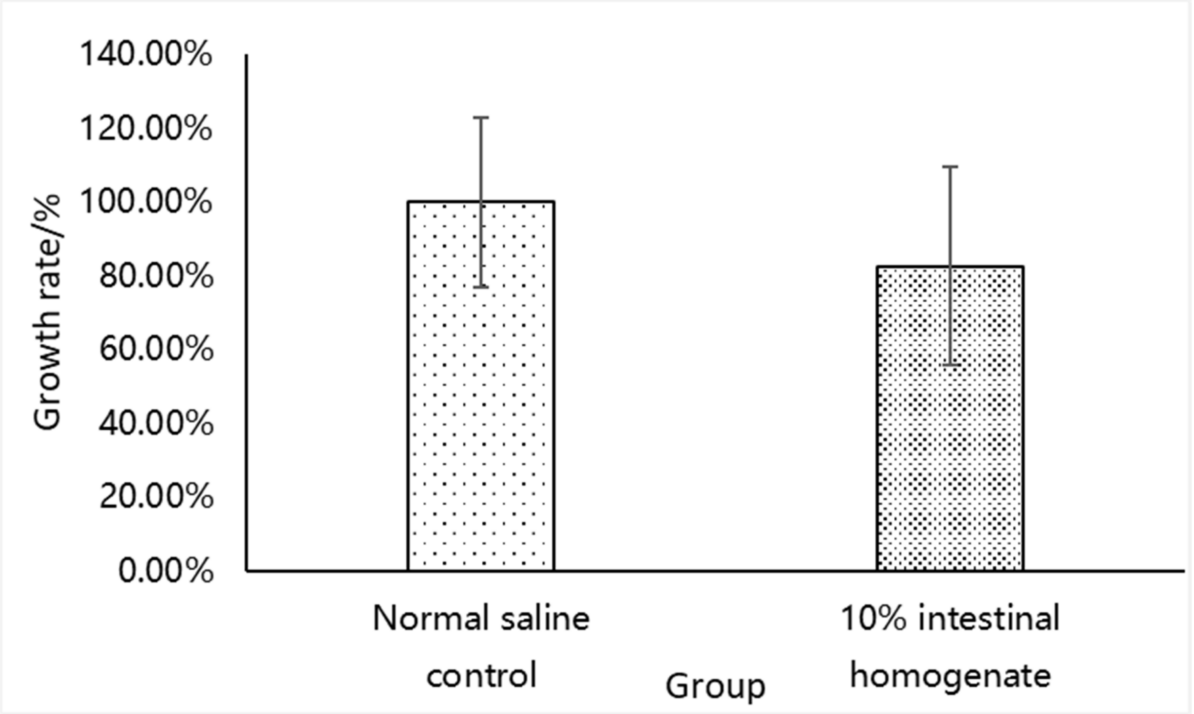

Figure 2. Comparison between the growth rate of Gs in the normal saline control and 10\% GI tract homogenate $(n=9)$ on the NA plate.

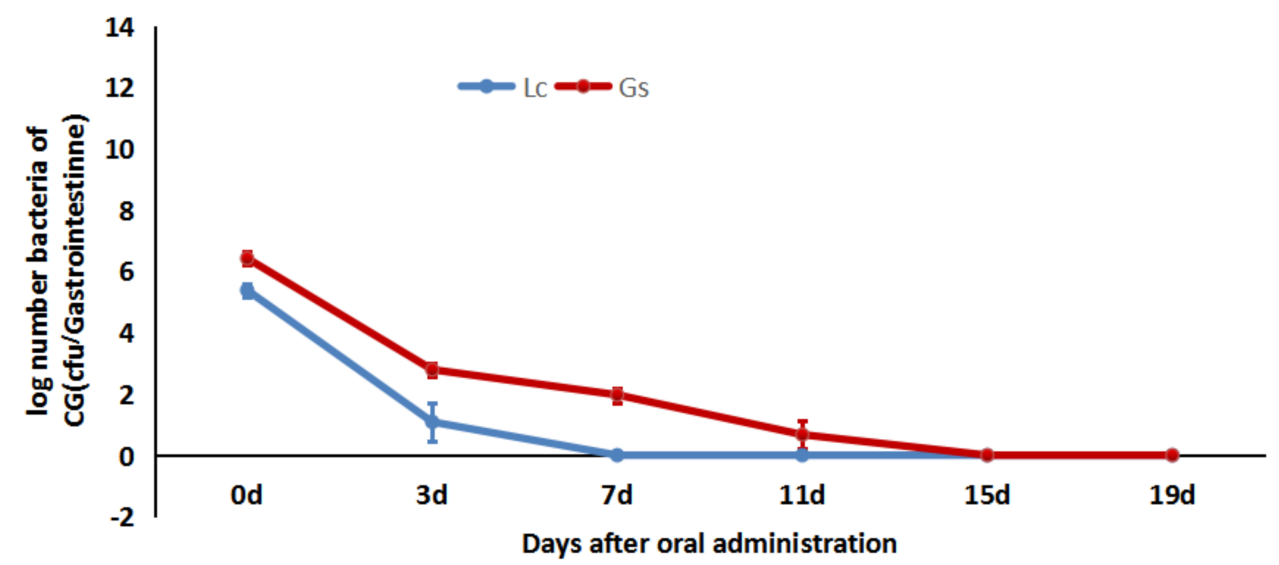

Figure 3. Kinetics of Lc and Gs elimination in the GI tract of crucian carp $(n=9)$. 


\subsection{Relative Abundance Changes of Lc and Gs in the Crucian Carp Gastrointestine}

Gastrointestinal content samples, collected at five time points during the three periods (from day -7 to day 21), were analyzed using a 16S RNA gene sequencing technique, and the results are shown in Figure 4. Lc was detected at very low abundance in the gastrointestine before the administration of the mixed diet (Day-7). It is not surprising that Lc became the major taxon in terms of abundance $(36.75 \% \pm 3.59 \%)$ after the administration of the mixed diet (day 0), whereas 7 days after the cessation of the mixed diet, the relative abundance of Lc decreased to $0.11 \% \pm 0.03 \%$. Fourteen days later, the relative abundance of Lc decreased to a very low level again, even lower than that of the control group (Figures 4 and 5).

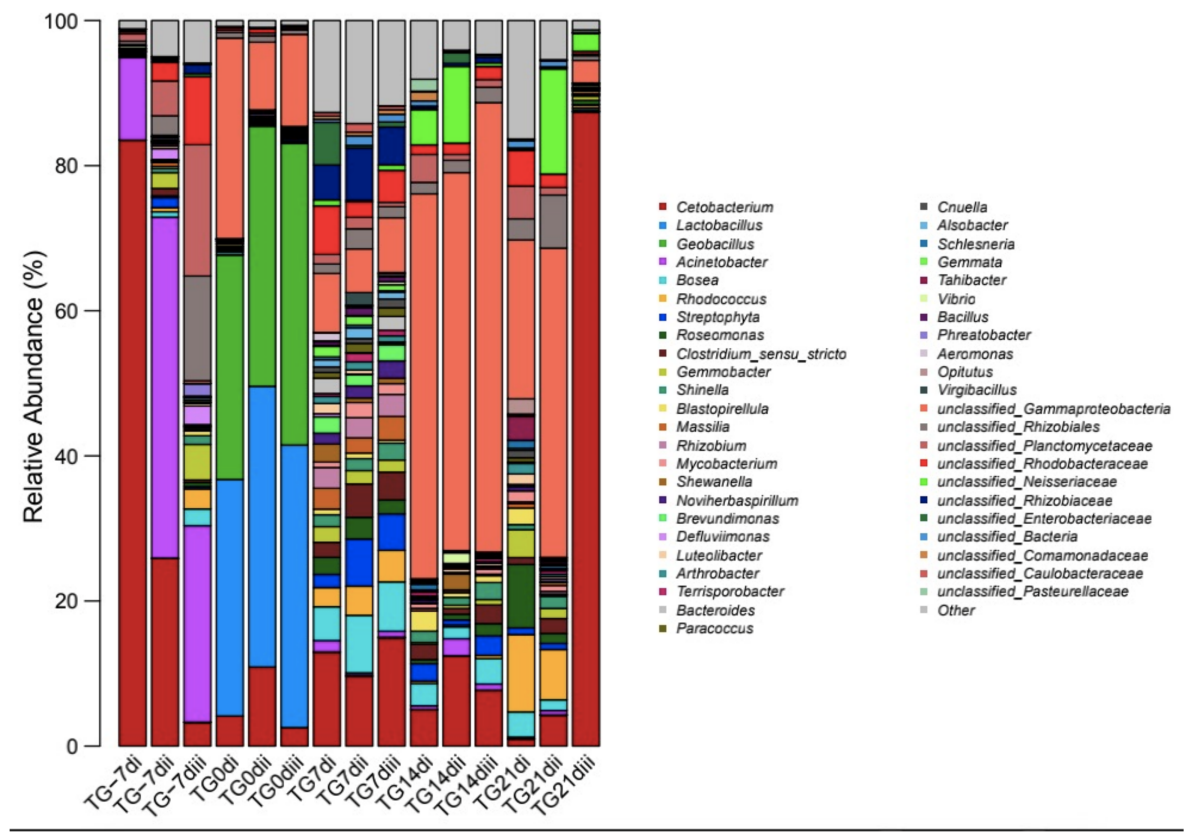

Figure 4. Bar plot illustrating the relative higher abundance bacterial genera for the individual fish. TG: treatment group: $-7,0,7,14$ and $21 \mathrm{~d}$ represent the sample time points; i, ii, and iii represent individual triplicates within a group.

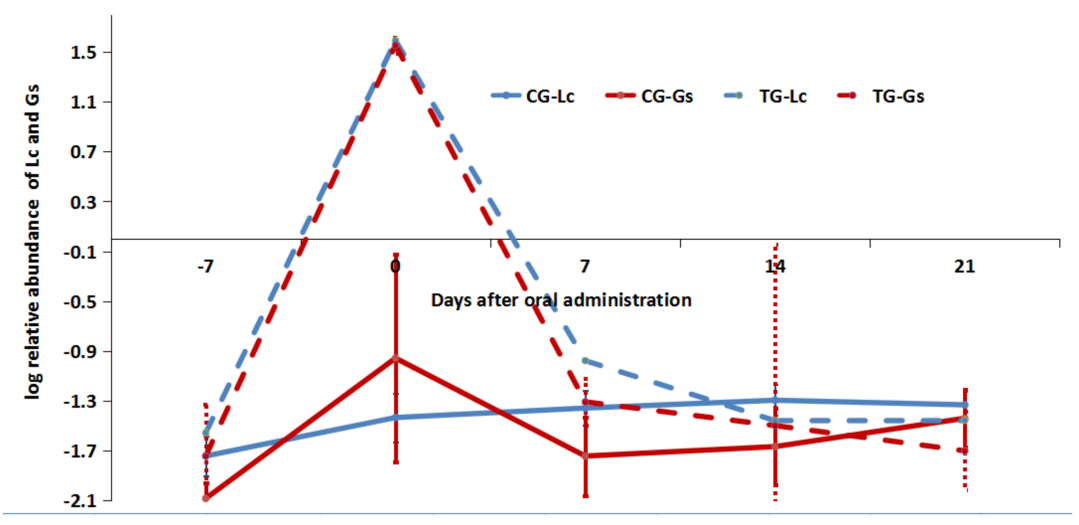

Figure 5. The changes in relative abundance of Lc and Gs in the CG and TG from day -7 to 21 .

The relative abundance of Gs had the same trend as that of Lc (see Figures 4 and 5). At day 0 , the relative abundance of Gs was $36.12 \% \pm 5.31 \%$, which was similar to that of Lc (Figure 5), but the number of viable Gs was eight times that of Lc (Figure 6). At day 7, although the relative abundance of Lc was $0.11 \% \pm 0.03 \%$, which was higher than other time points (except day 0), there was no viable Lc in the GI tract. We speculate that inactive Lc have reentered the GI tract because of the first incomplete replacement of the rearing water, and the same issue might also exist with the Gs. Viable Gs was detectable up to 
day 7, which is consistent with the results in Experiment 1. Regarding the control group, the relative Lc and Gs abundance remained at a very low level during the whole experiment, and no viable Lc and Gs were detected.

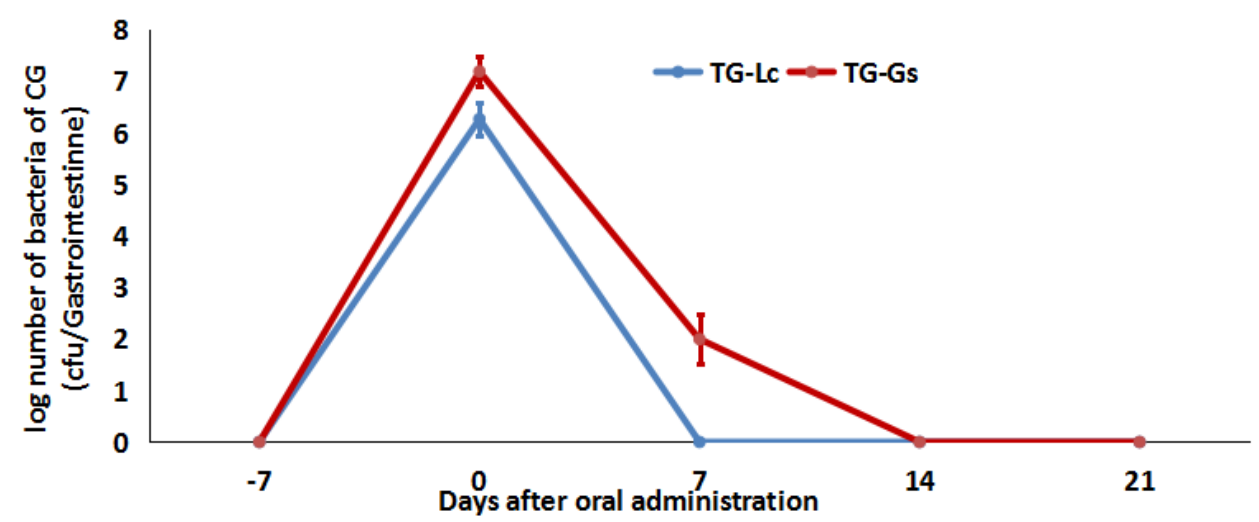

Figure 6. The changes in viable Lc and Gs bacteria in the TG from day -7 to 21 .

\section{Discussion}

Here, an improved, highly sensitive selective culture method was used to monitor Lc in the GI tract of crucian carp whereby interference from nontarget bacteria was eliminated. Meanwhile, a transit marker was used to assess Lc colonization. In addition, a highthroughput sequencing technique was used to further understand changes in the relative abundance of Lc and Gs.

\subsection{Elimination Interference Is Essential for Colonization}

Compared with terrestrial animals and humans, the intestinal microbiota of fish is more easily affected by feed and rearing water [3,28], Moreover, it is inevitable that there will be Lactobacillus and Bacillus in fish diet. Lactobacillus and Carnobacterium could be detected in the gut of control groups in a probiotic feeding trial [13]. Merrifield et al. [29,30] also reported that Enterococcus and Bacillus could be detected in the gut of rainbow trout that were fed a diet without probiotic supplementation, and they considered that these bacteria may be indigenous species. In the five commercial feeds, we detected different species of LAB and Bacillus at different concentrations. One of the feeds contained Pediococcus at $1.4 \times 10^{4} \mathrm{cfu} / \mathrm{g}$, and another feed contained Bacillus at over $10^{6} \mathrm{cfu} / \mathrm{g}$ (Table A2). Therefore, we proposed that sterile aquafeed should be used in GI microbe-related experiments. We therefore selected ${ }^{60} \mathrm{Co}$ irradiation, which is a good sterilization method recommended for its wide use in SPF animal feed [20].

In the experiment, the target bacteria were more likely to reenter the gut via residual diet or feces. Merrifield et al. [29] found that $7.4 \times 10^{3} \mathrm{cfu} / \mathrm{mL}$ of Bacillus and $4.3 \times 10^{3} \mathrm{cfu} / \mathrm{mL}$ of Enterococcus were detected in the rearing water after feeding the diet supplemented with these bacteria, despite $15 \%$ water renewal per $72 \mathrm{~h}$. Therefore, the authors suggested enhancing the water renewal rate to reduce background interference $[29,30]$.

In rearing water with a $\mathrm{pH}$ of 8.0-9.0, the concentration of the Lc decreased dramatically from $1.0 \times 10^{6} \mathrm{cfu} / \mathrm{mL}$ at the beginning to $<1 \mathrm{cfu} / \mathrm{mL} 7$ days later (unpublished data). Considering their short life in water, $100 \%$ water renewal with an interval of 5 days is enough to control the amount of these Lc in the water. However, if a testing strain can endure the water environment (such as in the case of a Gs spore) or even proliferate, the persistence time would be overestimated, and the reintroduction of the testing strain would be obvious. Thus, a better method for controlling the testing strain in water is needed.

\subsection{The Improved, Highly Sensitive Selective Culture Combined with a Transit Marker Is a Suitable Method for the Study of Colonization in Fish}

Various methods have been developed to evaluate bacterial colonization in complex gut microbiota. Although tagging probiotic strains with fluorescence markers is an alter- 
native, frequent plasmid loss during gut transition, low detection sensitivity and safety concerns hinder its further application. Species-specific PCR has also been developed to directly detect organisms in the extracted genome of fecal or GI tract samples. However, it cannot eliminate the baseline values of indigenous bacteria of the same species in their environments or diets [31]. At present, strain-specific PCR is used to detect and quantify strains; however, these strain-specific DNA fragments are based on a limited number of strains, making the strain-specificity robust only within a narrow confidence interval. These methods focus on humans and mice and are not suitable for colonization studies of aquatic animals such as fish. Although a selective medium method with colony identification is considered arduous and time-consuming, it is still a classic method in microbiology studies [32]. In particular, the method can tell whether the bacteria are alive or dead, whereas molecular methods cannot.

The MRS agar with a $\mathrm{pH}$ of 5.4-5.5 had high specificity and sensitivity for detecting acid-resistant bacterial species in the GI tract, such as the Lc strains used in our study. The weight of GI tract samples usually does not exceed $1 \mathrm{~g}$ after an appropriate starvation period when the bodyweight of the fish is less than $30 \mathrm{~g}$. Then, a $10 \%$ homogenate of less than $10 \mathrm{~mL}$ can be entirely spread on agar on fewer than 50 plates at $200 \mu \mathrm{L} /$ plate. The detection limit using this approach is $1 \mathrm{cfu} /$ gastrointestine. Other culture-dependent methods have poor accuracy and a detection limit usually higher than $10 \mathrm{cfu} / \mathrm{g}[13,15]$, whereas our improved selective culture method is very suitable for fish colonization experiments.

Colonization was defined by Conway and Cohen as the indefinite persistence of a particular bacterial population without the reintroduction of that bacterium [18]. If a microbe can exit the GI tract in the extreme long term (such as its whole life) or extreme short term (such as a couple of days), then the conclusion of colonization is not easy to make. However, if a microbe merely exits the GI tract for "a period of time", how should we define the length of that time? Marteau and Vesa [21] indicated that using a transit marker is necessary when studying the colonization of potential probiotics, and the colonizer should persist for a longer period than the marker. A Gs spore is a good transit marker $[21,25,26]$ for the following reasons: Firstly, its growing temperature ranges from 40 to $70{ }^{\circ} \mathrm{C}$ [33], so it usually cannot germinate, grow or reproduce in rearing water and fish gut. Secondly, the spores cannot be easily destroyed in the GI tract and feed preparation process. Thirdly, the spores can easily be counted based on high-temperature selective culture where other gastrointestinal bacteria usually cannot grow. Our study showed that the detection limit of Gs can reach $1 \mathrm{cfu} /$ gastrointestine.

\subsection{Monitored Relative Abundance Changes by High-Throughput Sequencing}

With the second-generation sequencing technique for gut microbiome community analysis, we can identify bacterial components at the genus level. Some researchers employed 16S rRNA amplicon sequencing to study colonization $[34,35]$. Howitt compared traditional microbiological cultures and $16 \mathrm{~S}$ polymerase chain reaction analyses for the identification of preoperative airway colonization in patients undergoing lung resection. The results showed that 16S PCR analyses identify colonizing bacteria in a similar proportion of preoperative BAL samples as traditional cultures [36]. An approach based on Illumina HiSeq $16 \mathrm{~S}$ rRNA amplicon was used by Xia et al. [11], with results showing that Lactococcus lactis JCM5805 was below the detection level after the cessation of probiotics for 5 days, and they inferred that this strain could not colonize the gut; rather, the evaluation of colonization based on the 16S rRNA amplicon technology that they used is limited, for two reasons. First, the detection level of the method on a fish's gastrointestinal sample is unknown. Metagenomics is only able to distinguish bacteria with concentrations greater than $10^{6}$ bacteria per gram of feces [37]; thus, some low-abundance bacteria would be missed by metagenomic analysis. Second, the method is based on DNA samples and cannot determine the viability of bacteria, i.e., whether the bacteria are alive or dead, which could influence the interpretation of the results [2]. Of course, this method is feasible as an auxiliary means to understand changes in the abundance of the target bacteria. 


\subsection{Lc ATCC 393 Cannot Colonize the Gastrointestinal Tract}

The persistence of probiotics in the gut is species-specific. In our previous study, even though an exogenous Bacillus licheniformis A1(Bli-A1) supplement was withdrawn, the concentration of Bli-A1 in the intestinal content was sustained at $3.3 \times 10^{2} \mathrm{cfu} / \mathrm{g}$ for at least 42 days with continuous sterile feed supplements [38]. In this study, when the detection limit was $1 \mathrm{cfu} /$ gastrointestine, the elimination speed of Lc was even faster than that of the transit marker, indicating that Lc could not colonize in the gastrointestine of crucian carp. This is consistent with our previous studies of Lc on catfish [27]. We speculate that there are three reasons that Lc could not colonize in the gastrointestine of crucian carp. First, indigenous microbiomes drive colonization resistance to probiotics and/or additional bacteria [39]. Second, Gastrointestinal contents are not conducive to Lc reproduction. Third, Lc lacks the ability to adhere to the mucosa of the GI tract of crucian carp.

However, the supplement of Lc changed the gastrointestinal microbiota structure of crucian carp (Table S1), compared with day -7 , the number of the high-abundant taxa $(\geq 1 \%)$ increased from 9 (except other bacteria abundance) to 24 (except other bacteria abundance) on day 7 , and recovered to the previous (day -7 ) microbiota structure until day 21.

\section{Conclusions}

The elimination speed of Lc was faster than the transit marker. Meanwhile, although Lc retained a low relative abundance from day $7(0.11 \% \pm 0.03 \%)$ to 21 in the crucian carp gastrointestine, they were not viable. The results indicate that the Lc ATCC 393 cannot colonize crucian carp. This study presents a method with a low detection limit for the colonization of $\mathrm{LAB}$ in fish and provides the idea of crucian carp to screen for beneficial probiotics.

Supplementary Materials: The following are available online at https: / www.mdpi.com/article/ 10.3390/microorganisms9122547/s1. Table S1: The supplement of Lc changed the gastrointestinal microbiota structure of crucian carp.

Author Contributions: Conceptualization, H.Z., H.W. (Haibo Wang) and Y.M.; methodology, H.Z., H.W. (Haibo Wang), J.S., L.X. and H.W. (Hongwei Wang); software, H.Z., X.M. and H.W. (Hui Wang); validation, X.M. and Y.L.; formal analysis, H.W. (Hui Wang); investigation, H.Z., H.W. (Haibo Wang) and Y.M.; data curation, H.Z. and H.W. (Hongwei Wang); writing-original draft preparation, H.Z., H.W. (Haibo Wang) and J.S.; writing-review and editing, H.Z., H.W. (Haibo Wang), Y.M., X.M. and H.W. (Hui Wang); visualization, H.Z., H.W. (Haibo Wang) and Y.M.; project administration, H.Z., Y.L. and L.X.; funding acquisition, H.Z. and L.X. All authors have read and agreed to the published version of the manuscript.

Funding: This study was funded by the Central Public-Interest Scientific Institution Basal Research Fund, grant number CAFS (NO. 2019A006), grant number CAFS(NO. 2020TD11), National Key Research and Development Program of China (NO.2017YFC1600704).

Institutional Review Board Statement: This study was approved by the Animal Care and Use Committee of the Green Fish Drug Innovation Center at the Chinese Academy of Fishery Sciences (ACUCFD2020-A06).

Conflicts of Interest: The authors declare no conflict of interest.

\section{Appendix A}

Table A1. Proximate composition of No.2 diet used in the experiment.

\begin{tabular}{cc}
\hline Proximate Composition & Proportion $/ \%$ \\
\hline Crude protein & not less than 33.0 \\
Crude lipid & not less than 5.0 \\
Crude fibre & not more than 8.0 \\
Crude ash & not more than 15.0 \\
Total phosphorus & not less than 1.1 \\
\hline
\end{tabular}




\section{Appendix B}

Table A2. Bacterial concentration of feed before ${ }^{60} \mathrm{Co}$ irradiation. $(n=3$; $\mathrm{cfu} / \mathrm{g})$.

\begin{tabular}{cccc}
\hline Feed & $\begin{array}{c}\text { General Heterotrophic } \\
\text { Bacteria/Lg cell Concentration }\end{array}$ & $\begin{array}{c}\text { Lactic Acid Bacteria/Lg } \\
\text { cell Concentration }\end{array}$ & $\begin{array}{c}\text { Thermophiles/Lg cell } \\
\text { Concentration }\end{array}$ \\
\hline No.1 & $4.84 \pm 0.35$ & $3.21 \pm 0.57$ & $4.00 \pm 0.65$ \\
No.2 & $5.50 \pm 0.41$ & $2.56 \pm 0.21$ & $4.22 \pm 0.19$ \\
No.3 & $4.29 \pm 0.24$ & $4.16 \pm 0.15$ & $3.80 \pm 0.21$ \\
No.4 & $6.48 \pm 0.39$ & $2.37 \pm 0.10$ & $4.37 \pm 0.28$ \\
No.5 & $4.70 \pm 0.36$ & $2.37 \pm 0.10$ & $2.94 \pm 0.35$ \\
\hline
\end{tabular}

\section{Appendix C}

Table A3. Bacterial concentration of feed at the beginning and end of the experiments (cfu/g).

\begin{tabular}{ccc}
\hline \multirow{2}{*}{ Feed } & \multicolumn{2}{c}{ Lg cell Concentration } \\
\cline { 2 - 3 } & Beginning & End \\
\hline L.casei/G. stearothermophilus (Experiment 1) & $7.0 / 6.9$ & $6.8 / 6.8$ \\
L.casei/G. stearothermophilus (Experiment 2) & $9.3 / 8.0$ & $9.1 / 8.0$ \\
\hline
\end{tabular}

\section{Appendix D}

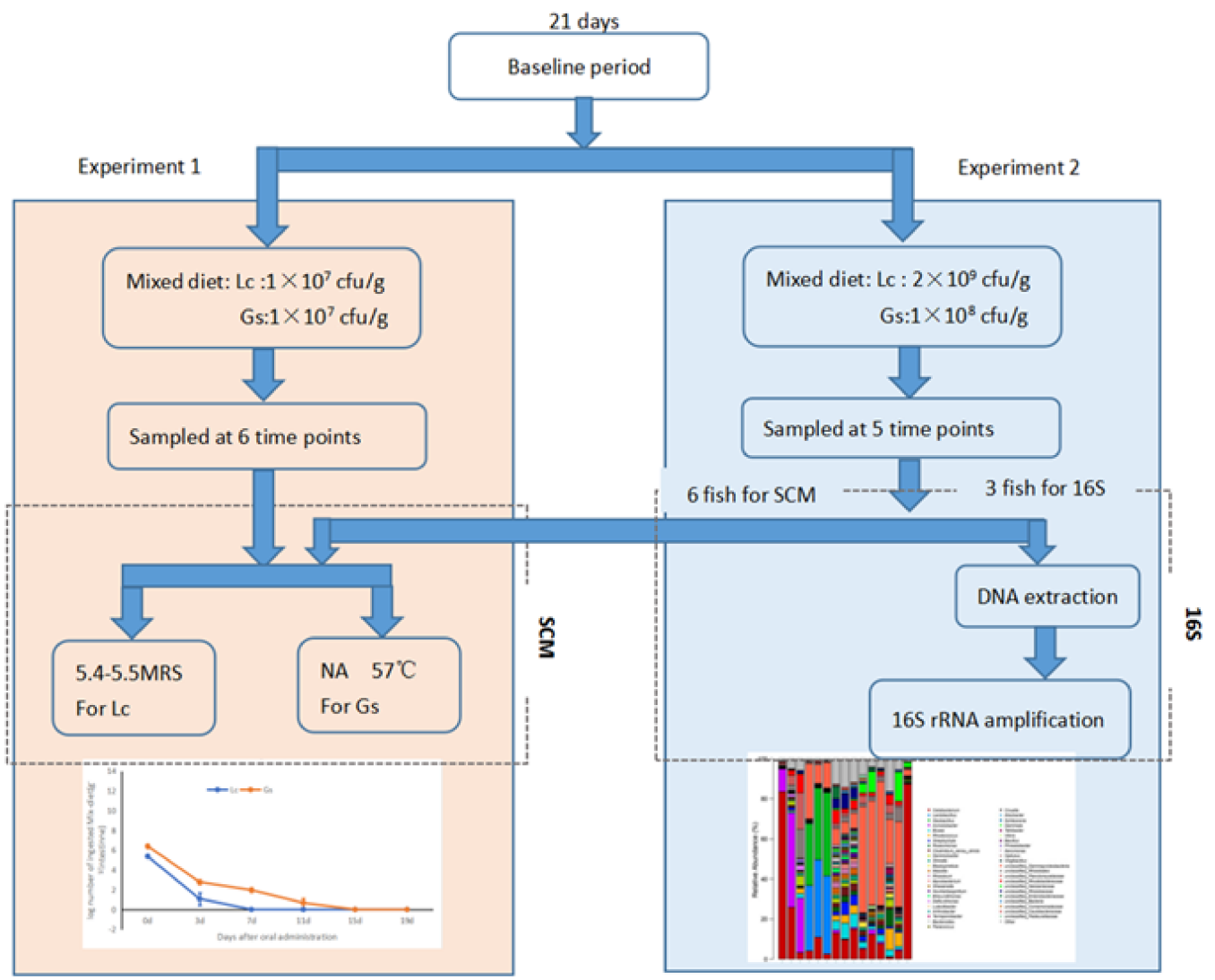

Figure A1. The flow chart of design of experiment. 


\section{References}

1. El-Saadony, M.T.; Alagawany, M.; Patra, A.K.; Kar, I.; Tiwari, R.; Dawood, M.A.O.; Dhama, K.; Abdel-Latif, H.M.R. The functionality of probiotics in aquaculture: An overview. Fish Shellfish. Immun. 2021, 117, 36-52. [CrossRef]

2. Vargas-Albores, F.; Martínez-Córdova, L.R.; Hernández-Mendoza, A.; Cicala, F.; Lago-Lestón, A.; Martínez-Porchas, M. Therapeutic modulation of fish gut microbiota, a feasible strategy for aquaculture? Aquacultrue 2021, 544, 737050. [CrossRef]

3. Li, X.; Ringø, E.; Hoseinifar, S.H.; Lauzon, H.L.; Birkbeck, H.; Yang, D. The adherence and colonization of microorganisms in fish gastrointestinal tract. Rev. Aquacult. 2019, 11, 603-618. [CrossRef]

4. Tian, J.; Kang, Y.; Chu, G.; Liu, H.; Kong, Y.; Zhao, L.; Kong, Y.; Shan, X.; Wang, G. Oral administration of lactobacillus casei expressing flagellin a protein confers effective protection against Aeromonas Veronii in common carp, Cyprinus Carpio. Int. J. Mol. Sci. 2020, 21, 33. [CrossRef] [PubMed]

5. Mehdinejad, N.; Imanpour, M.R.; Jafari, V. Combined or individual effects of dietary probiotic Pedicoccus acidilactici and nucleotide on growth performance, intestinal microbiota, hemato-biochemical parameters, and innate immune response in goldfish (Carassius auratus). Probiot. Antimicrob. Protein 2018, 10, 558-565. [CrossRef] [PubMed]

6. Zhao, D.; Wu, S.; Feng, W.; Jakovlić, I.; Tran, N.T.; Xiong, F. Adhesion and colonization properties of potentially probiotic Bacillus paralicheniformis strain FA6 isolated from grass carp intestine. Fisheries Sci. 2020, 86, 153-161. [CrossRef]

7. Mohammadian, T.; Alishahi, M.; Tabandeh, M.R.; Ghorbanpoor, M.; Gharibi, D. Changes in immunity, expression of some immune-related genes of shabot fish, Tor grypus, following experimental infection with Aeromonas hydrophila: Effects of autochthonous probiotics. Probiot. Antimicrob. Protein 2018, 10, 616-628. [CrossRef]

8. Zhao, L.L.; Liu, M.; Ge, J.W.; Qiao, X.Y.; Li, Y.J.; Liu, D.Q. Expression of infectious pancreatic necrosis virus (IPNV) VP2-VP3 fusion protein in Lactobacillus casei and immunogenicity in rainbow trouts. Vaccine 2012, 30, 1823-1829.

9. Balcázar, J.L.; Blas, I.D.B.; Ruiz-Zarzuela, I.; Vendrell, D.; Gironés, O.; Muzquiz, J.L. Enhancement of the immune response and protection induced by probiotic lactic acid bacteria against furunculosis in rainbow trout (Oncorhynchus mykiss). FEMS Immunol. Med. Microbiol. 2007, 51, 185-193. [CrossRef] [PubMed]

10. He, S.X.; Ran, C.; Qin, C.B.; Li, S.N.; Zhang, H.L.; Vos, W.M.D.; Ringø, E.; Zhou, Z.G. Anti-infective effect of adhesive probiotic lactobacillus in fish is correlated with their spatial distribution in the intestinal tissue. Sci. Rep. 2017, 7, 13195. [CrossRef]

11. Xia, Y.; Cao, J.M.; Wang, M.; Lu, M.X.; Chen, G.; Gao, F.Y.; Liu, Z.G.; Zhang, D.F.; Ke, X.L.; Yi, M.M. Effects of Lactococcus lactis subsp. lactis JCM5805 on colonization dynamics of gut microbiota and regulation of immunity in early ontogenetic stages of tilapia. Fish Shellfish. Immun. 2019, 86, 53-63. [CrossRef] [PubMed]

12. Huang, T.; Li, L.P.; Liu, Y.; Luo, Y.J.; Wang, R.; Tang, J.Y.; Chen, M. Spatiotemporal distribution of Streptococcus agalactiae attenuated vaccine strain YM001 in the intestinal tract of tilapia and its effect on mucosal associated immune cells. Fish Shellfish. Immun. 2019, 87, 714-720. [CrossRef]

13. Balcazar, J.L.; de Blas, I.; Ruiz-Zarzuela, I.; Vendrell, D.; Calvo, A.C.; Marquez, I.; Girones, O.; Muzquiz, J.L. Changes in intestinal microbiota and humoral immune response following probiotic administration in brown trout (Salmo trutta). Br. J. Nutr. 2007, 97, 522-527. [CrossRef] [PubMed]

14. Russo, P.; Iturria, I.; Mohedano, M.L.; Caggianiello, G.; Rainieri, S.; Fiocco, D.; Angel Pardo, M.; López, P.; Spano, G. Zebrafish gut colonization by mCherry-labelled lactic acid bacteria. Appl. Microbiol. Biot. 2015, 99, 3479-3490. [CrossRef]

15. Nikoskelainen, S.; Ouwehand, A.C.; Bylund, G.; Salminen, S.; Lilius, E. Immune enhancement in rainbow trout (Oncorhynchus mykiss) by potential probiotic bacteria (Lactobacillus rhamnosus). Fish Shellfish. Immun. 2003, 15, 443-452. [CrossRef]

16. Ringø, E.; Gatesoupe, F. Lactic acid bacteria in fish: A review. Aquaculture 1998, 160, 177-203. [CrossRef]

17. Ringø, E.; Van Doan, H.; Lee, S.H.; Soltani, M.; Hoseinifar, S.H.; Harikrishnan, R.; Song, S.K. Probiotics, lactic acid bacteria and bacilli: Interesting supplementation for aquaculture. J. Appl. Microbiol. 2020, 129, 116-136. [CrossRef] [PubMed]

18. Conway, T.; Cohen, P.S. Commensal and pathogenic Escherichia coli metabolism in the gut. Microbiol. Spectr. 2015, 3. [CrossRef] [PubMed]

19. Gatesoupe, F.J. The use of probiotics in aquaculture. Aquaculture 1999, 180, 147-165. [CrossRef]

20. Chen, Q.L.; Ha, Y.M.; Chen, Z.J. A study on radiation sterilization of SPF animal feed. Radiat. Phys. Chem. 2000, 57, 329-330. [CrossRef]

21. Marteau, P.; Vesa, T. Pharmacokinetics of probiotics and biotherapeutic agents in humans. Biosci. Microflora 1998, 17, 1-6. [CrossRef]

22. Banla, L.I.B.; Salzman, N.H.; Kristich, C.J. Colonization of the mammalian intestinal tract by enterococci. Curr. Opin. Microbiol. 2019, 47, 26-31. [CrossRef]

23. Safari, R.; Hoseinifar, S.H.; Nejadmoghadam, S.; Khalili, M. Apple cider vinegar boosted immunomodulatory and health promoting effects of Lactobacillus casei in common carp (Cyprinus carpio). Fish Shellfish. Immunol. 2017, 67, 441-448. [CrossRef] [PubMed]

24. Qin, C.B.; Xu, L.; Yang, Y.L.; He, S.X.; Dai, Y.Y.; Zhao, H.Y.; Zhou, Z.G. Comparison of fecundity and offspring immunity in zebrafish fed Lactobacillus rhamnosus CICC 6141 and Lactobacillus casei BL23. Reproduction 2013, 147, 53-64. [CrossRef]

25. Klijn, N.; Weerkamp, A.H.; de Vos, W.M. Genetic marking of Lactococcus lactis shows its survival in the human gastrointestinal tract. Appl. Environ. Microbiol. 1995, 61, 2771-2774. [CrossRef]

26. Vesa, T.; Pochart, P.; Marteau, P. Pharmacokinetics of Lactobacillus plantarum NCIMB 8826, Lactobacillus fermentum KLD, and Lactococcus lactis MG 1363 in the human gastrointestinal tract. Aliment. Pharmacol. Ther. 2000, 14, 823-828. [CrossRef] 
27. Zhang, H.; Wang, H.; Hu, K.; Jiao, L.; Zhao, M.; Yang, X.; Xia, L. Effect of Dietary Supplementation of Lactobacillus Casei YYL3 and L. Plantarum YYL5 on Growth, Immune Response and Intestinal Microbiota in Channel Catfish. Animals 2019, 9, 1005. [CrossRef] [PubMed]

28. Ringø, E.; Zhou, Z.; Vecino, J.L.G.; Wadsworth, S.; Romero, J.; Krogdahl, Å.; Olsen, R.E.; Dimitroglou, A.; Foey, A.; Davies, S.; et al. Effect of dietary components on the gut microbiota of aquatic animals. A never-ending story? Aquacult. Nutr. 2016, 22, 219-282. [CrossRef]

29. Merrifield, D.L.; Dimitroglou, A.; Bradley, G.; Baker, R.T.M.; Davies, S.J. Probiotic applications for rainbow trout (Oncorhynchus mykiss Walbaum) I. Effects on growth performance, feed utilization, intestinal microbiota and related health criteria. Aquacult. Nutr. 2010, 16, 504-510. [CrossRef]

30. Merrifield, D.L.; Bradley, G.; Baker, R.T.M.; Davies, S.J. Probiotic applications for rainbow trout (Oncorhynchus mykiss Walbaum) II. Effects on growth performance, feed utilization, intestinal microbiota and related health criteria postantibiotic treatment. Aquacult. Nutr. 2010, 16, 496-503. [CrossRef]

31. Xiao, Y.; Zhao, J.X.; Zhang, H.; Zhai, Q.X.; Chen, W. Mining Lactobacillus and Bifidobacterium for organisms with long-term gut colonization potential. Clin. Nutr. 2020, 39, 1315-1323. [CrossRef]

32. Goossens, D.A.M.; Jonkers, D.M.A.E.; Russel, M.G.V.M.; Stobberingh, E.E.; Stockbrügger, R.W. The effect of a probiotic drink with Lactobacillus plantarum $299 \mathrm{v}$ on the bacterial composition in faeces and mucosal biopsies of rectum and ascending colon. Aliment. Pharmacol. Ther. 2006, 23, 255-263. [CrossRef] [PubMed]

33. De Vos, P.; Garrity, G.M.; Jones, D.; Krieg, N.R.; Ludwig, W.; Rainey, F.A.; Schleifer, K.-H.; Whitman, W.B. Bergey's Manual of Systematic Bacteriology; Springer: Berlin/Heidelberg, Germany, 2009; Volume 3.

34. Zhang, X.; Wu, J.; Zhou, C.; Tan, Z.; Jiao, J. Spatial and temporal organization of jejunal microbiota in goats during animal development process. J. Appl. Microbiol. 2021, 131, 68-79. [CrossRef]

35. Crobach, M.J.T.; Ducarmon, Q.R.; Terveer, E.M.; Harmanus, C.; Sanders, I.M.J.G.; Verduin, K.M.; Kuijper, E.J.; Zwittink, R.D. The bacterial gut microbiota of adult patients infected, colonized or noncolonized by clostridioides difficile. Microorganisms 2020, 8, 677. [CrossRef] [PubMed]

36. Howitt, S.H.; Blackshaw, D.; Fontaine, E.; Hassan, I.; Malagon, I. Comparison of traditional microbiological culture and 16S polymerase chain reaction analyses for identification of preoperative airway colonization for patients undergoing lung resection. J. Crit. Care 2018, 46, 84-87. [CrossRef] [PubMed]

37. Amrane, S.; Lagier, J. Metagenomic and clinical microbiology. Hum. Microbiome J. 2018, 9, 1-6. [CrossRef]

38. Zhang, H.Y.; Wang, H.B.; Zhao, M.J.; Jiao, L.T.; Hu, K.; Yang, X.L.; Xia, L. Colonization of Bacillus licheniformis A1 in intestine of Ictalurus punctatus. J. Fish. Sci. China 2019, 26, 1136-1143.

39. Zmora, N.; Zilberman-Schapira, G.; Suez, J.; Mor, U.; Dori-Bachash, M.; Bashiardes, S.; Kotler, E.; Zur, M.; Regev-Lehavi, D.; Ben-Zeev Brik, R.; et al. Personalized gut mucosal colonization resistance to empiric probiotics is associated with unique host and microbiome features. Cell 2018, 174, 1388-1405. [CrossRef] [PubMed] 